REVIEW ARTICLE

\title{
Breaking the Scope-of-Practice Taboo: Where Multidisciplinary Rhymes with Cost-Efficiency
}

Nicholas Chadi*

INTRODUCTION

In the past century, medical care in the western world has evolved tremendously. While in the early 1900s, healhcare was mostly a priall developed nations. Complex structures have emerged: modern-day healthcare professionals now evolve in highly diverse environments ranging from small private clinics to highly specialized teaching hospitals. With the rising costs of healthcare and the rapidly increasing demand for healthto render the delivery of healthcare services more cost-effective without compromising the quality of care or patient and healthcare worker satisfaction. The challenge is superb; obstacles are numerous and solutions are often complex.

In recent years, many commissions and reports have strived to explore these obstacles and solutions. In Canada, the Final Report on the State of the Healthcare System (1), published in 2004, is one of many sources which support that the rigidity of healthcare structures and scope-of-practice rules-the rules defining which tasks different categories of healhcare professionals are permitted to perform-represents an ominous bartier to increas-

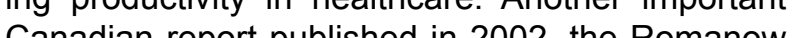
Report (2), also highights the need for change in the way healthcere services are delivered By in ing a special emphasis on "collaborative teams and networks of providers" the Romanow Report suggests that "traditional scopes of practice need to change [thereby suggesting] new roles for nurses, family physicians, pharmacists, case managers and ${ }^{*}$ To whom correspondence should be addressed:

${ }^{*}$ To whom corres
Nicholas Chadi

McGill University Faculty of Medicin

Montreal, QC, Canada, H3G 1 A4.
Email: nicholas chadi@mail.mcgill.ca a host of new and emerging health professions". While a certain number of studies have shown that ry care doctors) are very receptive to the idrimasharing part of their responsibilities with their fotlow healthcare professionals $(3,4,5)$ many others, often in fear of losing some of their autonomy exclusivity and prestige are still reluctant to suppor initiatives aiming to restrict or redefine the scope of their practice (6)

order to increase cost-efficiency in healthcare, the taboo surrounding physicians' rigid scopeof-practice should be broken; this would promote a stronger and more integrated multidisciplinary approach to medicine. The evidence supporting this thesis is growing at a breathtaking pace and revolves around five main themes. First, alterations to scope-of-practice rules fall into the very promising realm of catalytic innovations. Second, the redefinition of roles for healthcare practitioners-with a special emphasis on doctors, nurses and pharmacists-allows for better patient and healthcare practitioner satisfaction and improved healthcare resource utilization. Third, a new generation of physician assistants can successfully help address the issue of rising healthcare costs. Fourth, smartly organized mullidsciplinary leams can lead to better Finally a cerain number of compelling examples from the literature illustrate how multidisciplinary approaches have a high po how mul disciplingry better cost-effectiveness in healthcare.

CATALYTIC INNOVATIONS AND ALTERATION OF SCOPE-OF-PRACTICE RULES

$$
\text { Thanks to advances in technology, medi- }
$$
cal research is now able to target such complex issues as heart transplants, gene therapy and robotic microscopic surgery. Because of the impressive amounts of human and material resources involved in such "high-end, high-tech" innovative techniques, medical innovations tend to increase rather than decrease the costs of medical care (7). In an article published in the Harvard Business Review, Clayton M. Christensen, one of America's most influential business think and witers, describes such innovations as "sustaining innovation" (7). In his opinion, sustaining innovations are necessary to solve complex medical problems affecting small groups of patients in specialized medical chimneys, but they do not lead to decreases in medical costs. Christensen also goes a step further in affirming that in most developed countries, the omnipresence of sustaining innovations has led to the maintenance re "wedded in their current solvtions, delivery modes "wedded in the

In an interview with Mark D. Smith (Q), Christensen describes another category of innovations: disruptive innovations. Contrarily to sustaining innovations, disruptive technologies or services are available at much more affordable prices than existing alternatives. They "disrupt" the market by changing the approach to a problem and by bypassing more complex alternate solutions. They also allow the opening of a whole new market formed by purchasers who traditionally could not afford such products and innovations. In the same interview, Christensen depicts a third category of innovations-catalytic innovations-which he describes as being even more beneficial than disruptive innovations in the context of modern day healthcare. This third category of breakthroughs not only lowers the prices of products or services, but also focuses on bringing social change through scaling and replication (9). By making changes to rigid scope-of-practice fules, healthcare systems have the opportunity of creating a great number of catalytic innovalions. For example, by allowing a certain number of simple and highly reproducible medical acts that were traditionally completed by doctors, clinics can allow pationts to be treated at lower costs while avoiding long waits. Yes, this perspective allows for the posibility that patients might receive healthcare services of an inferior quality due to the fact that the healthcare professionals who are providing them do not have the same level of training as physicians. However in a North American context of limited resources where no less than $25 \%$ of doctors willingly affirm that their scope-of-practice is too wide (5), such catalytic innovations should definitely be considered as a promising avenue for addressing some of the most complex issues in healthcare.

REDEFINING THE ROLES OF HEALTHCARE PRACTITIONERS

In the past few decades, with the progressive lengthening of life expectancies and an ongoing "medicalization" of western societies (10) healthcare practitioners-and especially doctorshave been brought to play wider and wider roles in the lives of individuals. As mentioned above, this has led to important discrepancies between what healthcare professionals think their scope-of-pracconsists of on a day-to-day basis. To illustrate this point an article which was recently published in the American journal Health Affairs (3), maintains that American doctors, if asked the question: "what percentage of your time do you perform functions that require a medical degree?" would most likely provide a figure neighbouring $50 \%$. Building on this example, let's now further analyze how scope-ofpractice issues specifically impact the work of fou groups of key players of the healthcare workforce physicians, nurses, pharmacists and other healthcare professionals.

DOCTORS

Acknowledging the fact that physicians are ins one of the most important healthcare expenses for most industrialized nations $(11,12)$, there is no doubt that their time should be used wisely and that their practice should focus on what they do best. There appears to be a consensus in the medical Merature regarding the fact that where physician attention is the most essential is in the treatment diagnosis and management of complex medical

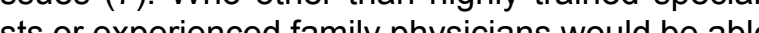
to correctly perorm a cardiac bypass surgery or detect a rare congenital disorder bringing subtle changes in a long followed patient's health?

However this simplified view of what physicians should be responsible for overlooks the fac that there are many levels of specialization inside the medical profession itself. While general practitioners and medical specialists might at first glance be assumed to work in collaboration-referring patients to one another when issues are either too broad or too specialized for their scope-of-prac- 
tice-recent evidence has shown that confusion often prevails when it comes time to determine who should be taking which role in the management of a patient's illness (5). Before moving on to redefining the scope-of-practice rules for nurses, pharmacists and other healthcare professionals, it is important to keep in mind that the medical profession itself has a highly varied array of members, each possessing different skills and levels of expertise. Thus, the elaboration of a strong stepped-care approach, where the right patients are directed to the right physicians for optimal healthcare, accompanied by the installation of adequate financial incentives for doctors to follow this approach, might very well be the necessary first step to any healthcare reform aiming to address scope-of-practice redef-
nition (5).

NURSES

While the diagnosis of medical conditions has traditionally been thought of as the most important aspect of a doctor's proctice, there is a growing body of evidence showing how simpler illnesses presenting with an easily identifiable pattern and consistent clinical findings can be managed very efficiently by nurses without the need for doctors to intervene directly (13). In fact, healthcare teams in which registered nurses work independently, yet in tight collaboration with practising physicians, have not only been reported to provide adequate healthcare services and diagnoses to patients; they have also been shown to do so with equal or increased levels of patient satisfaction, with no significant differences in clinical outcomes. Most importantly, these teams also yield the promise of improved cost-efficiency allowing for more medical acts performed by lower paid professionals (4).

Whereas doctors are often thought of as the ones who treat patients, nurses are often considered as the ones responsible for caring for patients. This observalion is usually correct, since a college vel diploma and focus moslly posseviding suppotive attention to palients in hospitals and out-patient settings (14).

However, increasing numbers of nurses who are trained and recognized as nurse practitioners are leading the way towards a new definition of nurses' roles. Benefiting from a higher level of "unique healthcare providers [...] who engage in advanced practices in a variety of specialty areas such as family, adult, paediatric, gerontologic, women's health, school health, occupational health, emergency, neonatal care and acute care" (13). Due to the great complexity and to the large number of areas where they can be affected, nurse practitioners (also referred to as nurse clinicians) typically complete their training in one of many different medical specialties. In Canada, most nurse practitioners complete a two year graduate university course which allows them to assess and manage a certain number of medical problems. For instance, their training can allow them to prescribe common pharmacological agents, make simple medical diagnoses or take charge of the management of patients with acute and chronic diseases while discussing such essential issues as health promotion and the Also, taking maintaining a healthy lifestyle (13) patients and of the larger amount of time they can palients and of the larger amount of time they can practitioners can develop highly efficient individur ized care plans in collaboration with their patients

Unfortunately, even though the early implementation of a new generation of nurse practitioners in healthcare institutions has led to very promising results in most industrialized countries (13) numerous obstacles including financial arguments and considerable opposition from organized medical associations are slowing down the process of training more advanced practice nurses. Some authors have brought the idea that one of the main reasons for the slow speed of development of specialized nursing training programs-which can very well be considered as high-yield catalytic in novations - might be that in the context of limited financial resources, nursing fellowships are not as "glamorous" as, say, the purchase of a new glisening MRI scanner or the development of a new artificial heart (8). Nonetheless, the fact that many governments are still adding more resources in highly specialized medical innovations which only that the a linhed number of patients indicates as programs reforming nurses' scope-of-proctice rules and advanced nursing training programs for coreasing healthcare costs is all too oflenigns for PHARMACISTS

Most North American pharmacists work in the private sector, often owning or co-owning heir own pharmacy. For many patients, doctors, led to the idea that pharmacists are not necessar- ily considered integral members of multidisciplinary healthcare teams (6). However, a converging body of recent publications has shown that increasing the degree of involvement of pharmacists in patient care yields tremendous potential. Whether they act autonomously as independent outpatient case managers or as part of multidisciplinary inpatient teams, pharmacists can most definitely represent a very valuable resource in an environment where

pharmaceutical products are becoming increas
ly diverse and more difficult to understand. When working in tight collaboration with physicians, pharmacists can allow for a much more comprehensive and cost-effective way of prescribing pharmaceutical products. In fact, in settings where pharmacists have successfully been inte"an improved availability of easy-to-interpret drug information, an perspectives regarding new and competing pharmaceutical products, more confidence about prescribing medications and more productive work relationships with pharmacists"(6). Furthermore from the patient standpoint, this has allowed major improvements in patient education through ways of a facilitated access to high quality drug-related information.

In two separate American studies observing the effects of integrating pharmacists in the care of patients with type 2 diabetes mellitus and chronic hypertension, pharmacists have been shown to lead the way towards better evaluation and modification of pharmacotherapy, better self-management of illness, improved reinforcement of screening for medical complications and better patient follow-up $(16,17)$. Also, in cases where pharmacists were involved in patient care they have been proven to allow better glycemic control, more sustainable lifestyle modifications and greater decreases in syswith bhrood pressure than in cases where patients with chroniciliciosses were cared for following a traas it was the case for nurses, all of these resuls, have been obtained with a high potential for significant cost reductions and improved overall costniffeant cost red

In light of these benefits, one might wonder why systematic reforms aiming to fully integrate pharmacists in healthcare teams haven't yet been undertaken. Once again, as it was the case for nurses, resistance from physician associations, which hesitate to disrupt the existing status quo, and the the major obstacles (6). One of the most commonly mentioned arguments relates to the increased time commitment required for physicians to interact with pharmacists on a regular basis. As one might readcance once a short period of adaptation has been completed.

OTHER HEALTHCARE PROFESSIONALS

While a great number of authors focusing on the effectiveness of multidisciplinary teams in healthcare have strived to describe the importance of programs involving such healthcare professionals as dieticians, physical therapists, occupationa therapists, psychotherapists and social workers the is sill a lack of evidence regarding the costffectiven and the changes in clinical outcomes related to the implementation of such programs (18). However there is no doubt that the highly trained professionals can play an important role in the management of patients in situations concerning their field of expertise. For instance, how often are family physicians required to provide nutritional, psychological or social counselling to patients in setting where they have very little time to do so? How often are patients given a note to consult a dietician, a psychotherapist or an occupational therapist without there being adequate-if any-followup from their family physician? If patient access to the healthcare professionals who are best able to help them is facilitated and if adequate financia incentives to stimulate collaboration are created here is a high potential for successfully decreasing the often overwhelming burden assumed by family

Finally, although the medical literature very seldom mentions the importance of well-traine and efficient administrative staff in assuring the ef feclive functioning of healthcare institutions, these actors can also contribute enormously to making care of responsibilities which can otherwise be perceived as very cumbersome tasks for other heathcare professionals (3), they should be more readily considered by their peers as essential members of a well-oiled medical team.

\section{TANTS} In the US and in an increasing number of professionals has recently made its entrance on 
the healthcare market and is being considered by many as a very appealing solution for addressing cost-efficiency issues in healthcare in the contex most commonly referred to as physician assistants, first entered the American medical system in the late 1960

Physician assistants, with their intermediate status, which places them somewhere in between doctors and nurses, have many advantages. Mainly, they allow palliating for an increased need for healthcare resources by taking over some of the tasks that were traditionally performed by sleepyeyed junior doctors, overwhelmed primary care physicians or overworked nurses (19). In the early 2000 s, there were close to 50000 fully trained phygovernestalis in the $u$. Thanks to favourable more and more specialized the energence of across the country, this number is rising consistently from year to year.

Most commonly, physician assistant degrees consist of 2 years of graduate university education training following a previous degree, most commonly in the area of biomedical sciences physiotherapy or occupational therapy. Students usually enter the program with a strong GPA, certain amounts of clinical work experience and strong interpersonal skills (20). In 2007, there were 136 state-recognized physician assistant programs in the US; $76 \%$ of them were at the master's level and offered what is often considered a broad-based "condensed medical degree" while the remaining $24 \%$ of the programs ofered doctoral or physician assistant raining specializing in a certain medical domain.

In the US, physician assistants usually work under the close supervision of fully certified physicians. While many of their tasks can overlap with nurses' job descriptions, they are usually not assigned to continuous patient care on hospital toward out atient groups are phert interentions townd oupatient groups or short interventions ries, completing full physical examinations, making simple clinical diagnoses, ordering laboratory tests, prescribing specific medications, suturing, applying casts, providing comprehensive patient education and doing rounds in nursing homes $(20)$ The results of physician assistant implementation in healthcare teams have been extremely promising throughout the world in all or most countries where they are present (19). In the UK, a small team of physician assistants has successfully provided a large number of patients with similar quality healthcare services as residents and docors. When asked, patients reported that they were highly satisfied with the attention they had received and were impressed by the empathy with which their healthcare providers had treated them. In addition, the doctors working with the team of physician assistants reported excellent professional ineractions with their new staff members, showed no esistance to the prolongation of their contract and were very appreciative of the help that they were providing them. Hence, by borrowing some of the simpler elements of physicians scope-of-practice, the wide scale implementation of physician assiscants worldwide might be one of the well-needed more cost-effective healthcare.

\section{ADVANTAGES AND POTENTIAL HURDLES OF}

\section{THE MULTIDSCIPLINARY APPROACH}

\section{ADVANTAGES}

Once all the players of a well-designed healthcare team have had a chance to collaborate in providing services for a certain period of time, the advantages of a multidisciplinary approach to healthcare are tremendous. However, achieving ing multidisciplinary team is all but a simple walk in the park. According to Regina E. Herzlinger, professor of Business Administration at Harvard, healthcare is still a tremendously fragmented industry (21). Nevertheless, Herzlinger writes that in the cases where successful horizontal integration of independent players is achieved, multidisciplinary care can generate economies of scale by considerably increasing efficiency while at the same time proving quality of care.

Multidisciplinary care has been shown to allow a stronger emphasis on preventative healthcare, pallont education and patient self-care. For nesses such as diabetes mellitus type II and hyperension requires an important component of patient education, which is considerably time and labourintensive. When physicians are forced to deal with such complex issues as lifestyle changes and en suring patient compliance to medical treatment without the help of other healthcare professionals, the costs of adequate disease management are quite astounding (4). In cases like these, the benefits of a strong collective approach to chronic disease management not only diminishes physicians' workload; it has also been proven repeatedly
to bring comparable or superior clinical outcomes such as lower levels of glycosylated haemoglobin A1C-the main laboratory indicator used for longterm monitoring of blood sugar control in diabetic patients $(15,17)$

Another reason for why improved healthcare outcomes can be reached when multidisciplinary approaches are used comes from the fact that teams comprising nurses, social workers and dieticians allow for patients to meet with healthcare professionals in a diferent setting than in a doctor's office, where they are more likely to understand and initiate meaningful lifestyle changes essential will often allow them to manage their illoss without needing to consult a doctor on a regular basis thus avoiding considerable healthcare expenses ( 9 ). Finally, one of the most important aspects of multidisciplinary care comes from the fact that it allows the elaboration of more comprehensive and efficient case management plans for patients. By definition, case management represents a "collaborative process that assesses, plans, implements, coordinates, monitors, and evaluates the options and services required to meet an individual's health needs, using communications and available resources to promote quality and cost-effective outcomes" (17). For instance, these "communications and available resources", sometimes referred to as telemedicine, comprise such practices as telephone counselling, email exchanges and webbased health services, all of which can be delivered effectively by more than one member of healthcare teams. The number of studies assessing the costeffectiveness of intensive case management is sill very limited. Nevertheless, a fair number of trials have suggested that when patients are taken in charge by a multi-liered team, they are much tions, thus to stay away from acule medical situaamounts of healthcare resources $(4,18)$.

\section{POTENTIAL HURDLES}

Thes approaches to healthcare can also come with significant drawbacks, a large number of which have been reported on many occasions in the medical literature and the object of which is beyond the scope of this article. In fact, all of the above-mentioned advantages of team-based a significant number of hurdles. Most importantly, individual physician and physician association approval needs to be obtained before any majo 作 can be made. When it comes to changes of this nature, doctors have traditionally adopted a very conservative mentality and usually request concever envisioning undertaking major shifts in their practices (22). Furthermore, the risks of obtaining suboptimal results in early stages of multidisciplinary care program implementation and in the period of time following scope-of-practice changes are often considered as an unbearable short-term gamble which healthcare authorities are not always ready to take, especially without the presence of solid eviinitiatives are enting to trace the advancement of multidisciplinary healthcare there is still a pressing need for more credible and unbiased evidence comparing the two sides of the medal in order for industrialized nations to move ahead with ambitious multidisciplinary healthcare reforms.

\section{PROMISING EXAMPLES FROM THE MEDICAL} LITERATURE

More and more healthcare practitioners and entrepreneurs are starting to acknowledge the potential of catalytic multidisciplinary healthcare reforms and innovations. In North America alone, many states and provinces have made clear mention of their intention of embracing new multidisciplinary paths or have clearly underlined the need or a redefinition of scope-of-practice rules $(1,2)$. Here are three examples of promising Canadian and American initiatives which have recently made their way into the medical literature.

\section{ONTARIO FAMILY HEALTH TEAMS}

In 2009, almost 2 million Ontarians had access to comprehensive family healthcare throug These teams, created by indendent groups healthcere practitioners since the beginning of the years 2000 , have received numerous incentives and generous support from their provincial govern ment. In fact seeking to improve accessibility to primary healthcare for its citizens, the Ministry of Health of Ontario has created a vision allowing phy sicians, nurse practitioners and other members of the team to practice in a productive working environment where cooperation and knowledge exchang are extremely important. Among other roles, Family 
Health Teams are meant to promote disease management programs for chronic illnesses, self-care programs, health promotion, patient-centered care and facilitated navigation and care coordination for patients seeking services in multiple healthcare institutions.

Although the implementation of Family Health Teams in Ontario has been welcomed almost unanimously by citizens and healthcare practitioners, there still exists an important gap between the reality of practising in a team-based setting and what is taught to medical and nursing students in Ontarian medical and nursing schools (24). Hence, even though they are extremely promising, multidisciplinary approaches to medicine need not only be implenented on the field, they also need to be education in order to ensure that the new generation of workers will be belter equipped to deal with the new challenges of team-based practice.

MINUTE CLINICS

In the US, a very popular example of how scope-of-practice rules have been changed in order to provide patients with more affordable and convenient healthcare services is the advent of socalled "Minute Clinics" (21). These clinics are run entirely by nurse practitioners who use softwarebased protocols in order to offer vaccinations and basic medical attention for a limited set of health problems. If a patient presents with an illness that she is immediately referred to a doctor's office or emergency room.

Many factors can explain the booming success of this catalytic innovation which has successfully reformed scope-of-practice rules for nurses in the US. First, Minute Clinics offer cheaper, quicker and more accessible healthcare for a great number of ilinesses allowing patients to avoid more costly and inconvenient vists to the hosplal. Second, tance from physians, simply because they are not seen as a thret to their praclice; rather they allow for the shortening of waiting lists and allow doctors to focus on more complex cases requiring more of their competencies and skills. Third, minute clinics are often used by uninsured, underserved populations who otherwise would not have access to other healthcare resources. Finally, according to surveys, patients are equally if not superiorly satisfied with the quality of care they receive in Minute Clinics. (8).
KAYSER PERMANENTE

A recent article published in The Economist, entitled Another American Way, draws an extremely flattering picture of Kaiser Permanente, an integrated American healthcare firm which offers managed care packages to 8.6 million Americans via efficient primary healthcare teams (25). Each team follows a group-practice model composed of 3 to 5 clinicians (physicians, nurse practitioners or physician assistants), 2 registered nurses, 1 to 2 receptionists or clerks and 6 to 7 registered practical nurses or medical assistants that provide care to ample of 8000 to 15000 patients (22). One of Kayser Permanente's biggest strengths is that it of in team its employees a comprehensive training Also, teams have the freedom to adapt to the needs and conditions of their patient population. For intan a team can decide to hire more or less physicians, more non-physician clinicians or more support staff depending on the patterns of illness contracted by the population it serves. In addition, each primary healthcare team receives a thoroug report of its activities every three months, outlining patient and staff satisfaction as well as clinical outcomes. Monetary incentives and feedback are then provided by Kayser Permanente's headquarters with the effect of promoting constant progress and improvement among healthcare teams.

\section{CONCLUSION}

Considering the size of the challenge of controlling healthcare expenses in a context of growing healthcare needs and aging demographcs, the application of new ways to improve the cost-effectiveness of healthcare systems is essential. One of the most promising avenues suggests that doctors should be encouraged to review the rules regulating the scope of their practice in order to promote a stronger multidisciplinary approach to healthcare. In ocurts, health sorulon to tions should strive to follow the model of catalytic inn a molel encouraing both simpler and more affordable solutions with a special emphasis on social change. In addition, scope-of practice reforms should not be limited to physicians; rather, they should extend to all healthcare practitioners. Also, the potential benefits of training a new gen eration of physician assistants should be acknowtedged. All of these elements have the potential of giving rise to an efficient and visionary multidisciplinary approach to healthcare. Based on the large number of positive accounts taken from the medical literature, reforms that follow the idea of multidisciplinary approaches to healthcare should definitely be undertaken: the benefits of such enterprises seem to widely out-measure the potential obstacles and hurdles which might affect their implementation.

At this point on the road, one might wonder: Where to start? What should be the next big step? While governments are striving to adapt their healthcare systems to the realities of the 21 st century, the answer to these questions might very well lie in the hands of those who are in the best position to implement change in the years to come: students. If medical and nursing students become aware of the potential benefts of redefining the which has traditionally surrounded the matter they might just become the much need change capable of increasing the costefficiency of 21 st century healthcare.

\section{REFERENCES}

Kirby MJL. The Health of Canadians - The Federal Role, Final Report on the State of the Healthcare System in Canada, October 2002. URL: http://www.parl.gc.ca/37/2/parlpdf

2. Romanow Q.C. RJ. Building on Values: The Future of Healthcare in Canada - Final Report. Saskatoon: Com2002. URL: http://dsp-psd.pwgsc.gc.ca/Collection/CP3285-2002E.pd

3. Margolius D, Bodenheimer T. Transforming Primary Care: From Past Praclice To The Practice Of The Future. healthaffairs.org/cg/content/abstract/29/5/779

Litaker D. Physician nurse practitioner teams in chronic disease management: the impact on costs, clinical effectiveToss, and palients perception of care. Jounal of interponih.gov/pubmed/12850874

5. Katon W. Vor Kolf M Lin E Simon G. Rethinking pracitioner roles in chronic illness: the specialist. primg pract physician, and the practice nurse General Hospita Psychiatry. 2001:23:138-44. URL: http///www sciencedirectcom/ science? Ob=MImg\&_imagekey=B6T70-439VBXW-5-18 cdi $=5044 \&$ user $=458507 \&$ pii $=\$ 0163834301001360 \&$ orig=search\& coverDate $=06 \% 2 F 30 \% 2 F 20018$ sk $=999769996 \& v i e w=c \& w c h p=d G L b V Z W-z S k z S \& m d 5=0$ 5d2b705d87abfd98a1b751a965f129d\&ie=/sdarticle.pdf
6. Pottie K, Farrell B, Haydt S, Dolovich L, Sellors C, Kennie $\mathrm{N}$, et al. Integrating pharmacists into family practice teams: Physicians' perspectives on collaborative care. Can Fam Physician, December 1, 2008;54(12):1714-17175. URL http://cfp.highwire.org/cgi/content/abstract/54/12/1714

. Christensen $\mathrm{CM}$. Will disruptive innovations cure healthcare? Harvard business review. 2000;78(5):102. URL: http://nyc. indymedia.org/media/application/disrup tivechangeinhealthcare-thumb.pd

Christensen CM. Disruptive innovation for social change Harvard business review. 2006;84(12):94. URL: http://faculty.miis.edu//levinger/dissuptive_innovation.po

Smith MD. Disruptive innovation: Can healthcare learn from other industries? A conversation with Clayton $\mathrm{M}$ Christensen. Health Affairs. 2007,26(3):w288. URL: http:// content.healthaffairs.org/cg/content/full/26/3/w288? ijkey=

- Conad P. Medicalzation and Social Control. Annual Re hals annualreviews. 0 rg/doipdf/10.1146/annurev.so 18080 192.001233?cookieset $=1$

11. Burton Rachel and Peterson, Chris L. U.S. Healthcare Spending: Comparison with Other OECD Countries, Congressional Research Group, September 17, 2007. URL http $/ / /$ digitalcommons ilr cornell edu/cgi/viewcontent. cgi?article=1316\&context=key_workplace

12. Pearson, Mark. Disparities in health expenditure across OECD countries: Why does the United States spend so much more than other countries. Written Statement to Senate Special Committee on Aging, Health Division, OECD 30th September 2009. URL: http://www.oecdwash.org/PDFILES/Pearson_Testimony_30Sept2009.pdf

3. Buchan J. Skill-mix and policy change in the health workforce: nurses in advanced roles, OECD Health Working Papers, 2005. URL: http://www.oecd.org/dataoecd/30/28/33857785.pd

14. Association CN. 2007 Workforce profile of Registered Nurses in Canada. Canadian Institute for Health Information, July 2009. URL: hitp://www.cna-ailic.ca/CNA/documents/parfpublications/2007_RN_Snapshot_e.pdf

5. Hogg W. Randomized controlled trial of Anticipatory an Preventive multidisciplinary Team Care: For complex padian family physicion. 2009-55(12) of cercolrepint5/12070

. Sookan Rnun P, Richards RM, Sanguansermsri J, Teerasut C. Pharmacist Involvement in Primary Care Improves
Hypertensive Patient Clinical Outcomes. Ann Pharmacother. December 1, 2004:38(12):2023-8. URL. http.//mmw theannals.com/cgi/content/abstract/38//12/2023

17. Hayward RA. Proactive case management of high-risk patients with type 2 diabetes mellitus by a clinical pharmacist: a randomized controlled trial. The American journal of 
managed care. 2005;11:253. URL: http://drtedwilliams.ne/ cop/727/diabetes\%20disease\%20management\%203 pd 8. Gray D, Armstrong CD, Dahrouge S, Hogg W, Zhang W. Cost-effectiveness of Anticipatory and Preventive multidisciplinary Team Care for complex patients: Evidence from a randomized controlled trial. Can Fam Physician. 2010 January 1, 2010;56(1):e20-9. URL: http://cfp.highwire.or cgi/content/abstract/56/1/e20

19. Stewart A. Can physician assistants be effective in the UK Clinical medicine. 2005;5(4):344. URL: http://docserver. ingentaconnect.com/deliver/connect/rcop/14702118/v5n s13.pdf?expires $=12733710108$ \& $=566607138$ trtiteid $=520$ 003\&accname $=$ McGill+University+Library+-+Serials $+\% 2$ 6+E-ResourcestUnilechecksum=609B20671D98482650 उCO2DOOBECAISB

. Jones PE. Physician Assistant Education in the United States. Academic Medicine. 2007;82(9):882-7 10.10971 ACM. tant_Education in the United_States 14 aspx

Nicholas Chadi (M.D., C.M. candidate 2012) is a third year medical student at McGill University.
21. Herzlinger RE. Why innovation in healthcare is so hard. Harvard business review. 2006;84(5):58. URL: http://hbr. health-care-hard.pdf

22. Grumbach K, Bodenheimer T. Can Healthcare Teams Improve Primary Care Practice? JAMA. March 10 2004;291(10):1246-51. URL: http://jama.ama-assn.org/cg// content/abstract/291/10/1246

23. Care Ontario Ministry of Health. Roadmap to Implementing a Family Health Team, June 23 2009. URL: http://hd. handle.net/1873/15110

24. Soklaridis S, Oandasan I, Kimpton S. Family health teams: Can health professionals learn to work together? Can Fan Physician. 2007 July 1, 2007,55(7).1198-9. URL: http:/ whw.ctr.ca/cg/cilmgr?gca=cip,53/7/198

Eon can Way. The Economist. Aphi 29, 2010. URL: http://www id $=16009167$ \&source=hptextfeature
The Canadian Space Agency (CSA), via its Space Leaming Program offers a bevy of opportunities that Can Through the

Through the Space Learning Grants Program, of 200 , majority being supports their participation in space-focused learning initiatives. This grant program, designed to assist students with funds to help cover travel, registration and living expenses, is open to students from primary school right up to the doctorate level, so long as the student is either a Canadian citizen or permanent resident of Canada.

Over the past year, funding awarded through this program has allowed students to participate in a wide variety of initiatives covering an array of fascinaling disciplines - from an annual Aerospace Medical Association Meeting, and international Lunabotics competitions to Solar-

While individual requests for funding can be submitted and considered, budget-permitting, on an ad-hoc basis year-round, there are also two opportunities both earmarked and funded through this program on an annual basis.

The first is the International Astronautical Congress (IAC) - the largest annual international space confere. Each year in February, students relevant conference topics that will also allow them to highlight their research at the congress. Each abstract undergees an internal evaluation by CSA scientists, engineers and medical professionals with those achieving the highest rankings *To whom correspondence should be addressed:
Jason Clement Canadian Space Agency forwarded to the International Astronautical federation (IAF) - the organization responsible Fo abtracts were submitted for consideration to be included at the congress in Cape Town South Africa, with 21 Canadian students ultimaly being selected for funding by the Canadian Space Agency to share their work with the conference delegation of international space professionals and other students. For anyone interested in applying to the 2012 edition of IAC , to be held in Naples, Italy, information on the application process will be posted on the student $(17+)$ section of the CSA web site in the late fall.

A second learning opportunity funded by the CSA is the NASA Academy summer program. NASA Academy provides students at the upper undergraduate or early graduate levels with an opportunity to spend 10 weeks paired with a esearcher at one of the NASA centres. Students selected to participate are given the extraordinary opportunity to conduct space research with an experienced researcher in addition to developing their own group project with fellow students. NASA Academy participants are treated to a wonderful introduction to the space field through a series of presentations, meetings and visits at the ane past two years, two McGill students have b. In the past wo years, tis competitive process student Laura Drudi in 2010 and Atmedica Science student Alexandra Anderson-Frey for the summer of 2011. Information for those interested in applying to the 2012 NASA Academy will also be available via the student section of the CSA web site in the fall.

Finally, the My Research section of the CSA website profiles the next generation of space leaders, providing a showcase for students involved in space-related research. The profiles 